Towards an integrative approach to communication styles: The Interpersonal Circumplex and the Five-Factor Theory of personality as frames of reference

by A. Waldherr \& P. M. Muck

To cite this article:

Waldherr, A. \& P. M. Muck (2011). Towards an integrative approach to communication styles: The Interpersonal Circumplex and the Five-Factor Theory of personality as frames of reference.

Communications, 36 (2011), 1-27.

Published in:

Communications (Link to article)

Copyright:

The Authors, 2011

DOI:

10.1515/comm.2011.001 


\title{
Towards an integrative approach to communication styles: The Interpersonal Circumplex and the Five-Factor Theory of personality as frames of reference
}

\author{
ANNIE WALDHERR and PETER M. MUCK \\ E-mails: annie.waldherr@fu-berlin.de; peter.muck@uni-bielefeld.de
}

\begin{abstract}
This article reviews existing approaches to defining and distinguishing communication styles and proposes a common frame of reference for future research. The literature review yields two schools of thought: the behaviorcentered perspective and the personality-oriented perspective. Although these lines of research differ in their ways of defining communication styles, they show considerable similarities with respect to their classification. Many researchers build their taxonomies on two key dimensions: assertiveness and responsiveness. We propose embedding communication styles into the Five-Factor Theory (FFT) and defining them as characteristic adaptations of personality. We also suggest the Interpersonal Circumplex (IPC) as a reference model for distinguishing communication styles as it is able to integrate substantial dimensions and facets of existing taxonomies in a parsimonious way.
\end{abstract}

Keywords: communication style, Interpersonal Circumplex, Five-Factor Theory, communication and personality

\section{Introduction}

Communication competence is an important social skill in professional and private life. Today, various educational institutions offer training to improve communication behavior, e. g., for managers, health professionals, teachers, or married couples. However, training often gives the same guidelines for communication behavior to all persons, neglecting individual differences in personality, socialization, or culture. Therefore, one endeavor of academic research on interpersonal communication is to find and describe individual differences in communication behavior. Only by knowing the current communication style of a person can help- 
ful advice be given on how to reasonably change communication behavior.

A variety of concepts for defining and describing communication styles has evolved since the late 1970s in such diverse fields as educational communication (Inglis, 1993; Norton, 1983), intercultural communication (Gudykunst et al., 1996; Leung and Bond, 2001; Park and Kim, 2008), health communication (Kettunen, Poskiparta, and Liimatainen, 2000), and management communication (Baker and Ganster, 1985; Bednar, 1982). During the last decade it has been criticized that to date no common and widely accepted model of communication styles has emerged (Daly, 2002; Daly and Bippus, 1998; de Vries, Bakker-Pieper, Alting Siberg, van Gameren, and Vlug, 2009; Leung and Bond, 2001).

With this article, we want to contribute to the search for an integrative model by reviewing and synthesizing existing approaches to communication style. Our research questions are twofold: (1) How can we define communication style? (2) How can we distinguish different communication styles? The former question refers to the problem of definition and also tackles the question of how the construct of communication style is embedded in a broader theoretical context and how it relates to other constructs like personality traits or specific behavior. The latter question addresses the problem of description. Here, we search for comprehensive models that describe and structure individual differences in communication style.

We understand interpersonal communication as a circular process with both interaction partners alternately acting as communicator and recipient (Schramm, 1954). Individuals differ in their ways of encoding, interpreting, and decoding messages. Since these processes are internal and hardly observable, we posit that a model of communication styles should mainly focus on overt communication behavior. Therefore, we searched for models concentrating on message patterns conveyed in the communication process, the term 'message' including not only verbal content (i. e., what is said), but also paraverbal and nonverbal behavior (i. e., how it is said). This is all the more important with respect to future empirical studies, as it makes it possible to conduct not only self-rating surveys but also other-rating and observational studies. However, we also searched for theories that analyze the influence of personality and situation on communication behavior so that differences in overt communication behavior are not only described but also explained.

The first part of the paper is devoted to a review of the existing body of research. We distinguish two schools of thought that differ in their way of defining communication style. Whereas one line of research treats communication styles as recurring behavioral patterns, others view communication style as the way a person displays personality traits. In the 
second part of the paper, differences and similarities of the existing approaches in defining and describing communication styles are discussed. We suggest two integrative concepts (i.e., the Five-Factor Theory and the Interpersonal Circumplex), and we propose a circumplex model of communication styles to guide future research in the field.

\section{Communication styles as recurring behavioral patterns}

A first group of researchers agrees that communication styles can be defined as recurring behavioral patterns. In this section we include research from as diverse fields as educational and cross-cultural communication that emphasize environmental and cultural influences on communication style.

Norton (1978) was the first to introduce the term communicator style as "the way one verbally or paraverbally interacts to signal how literal meaning should be taken, interpreted, filtered, or understood" (Norton, 1978, p. 99). Thus, he defined communicator style as a relatively stable pattern of verbal and nonverbal interaction associated with a specific individual and influenced by cultural role expectations.

Norton (1983) distinguished nine communicator styles (cf. Table 1) and a general sub-construct called communicator image that describes to what extent a person thinks of him- or herself as a good communicator. $\mathrm{He}$ arrived at this classification by condensing and clustering numerous style variables that he inferred from existing concepts on interpersonal communication and interpersonal behavior (Bales, 1970; Leary, 1957; Schutz, 1958 amongst others). Norton operationalized his concept with the Communicator Style Measure (CSM) for which he reported various validation studies in his 1983 book. Although scholars have criticized the partially low internal reliabilities of Norton's scales (Baker and Ganster, 1985; Horvath, 1998; Rubin, Palmgreen, and Sypher, 1994; Talley and Richmond, 1980), Norton's definition and description of communicator styles have been very influential in the field. It has motivated a lot of studies especially in the areas of educational (e. g., Inglis, 1993; Sallinen-Kuparinen, 1992) and organizational communication (Baker and Ganster, 1985; Bednar, 1982; Infante and Gorden, 1989).

Hansford and Hattie (1987) examined the structure of five communicator style dimensions (dominant, impression leaving, relaxed, animated, and attentive) and found two underlying higher-order factors by conducting second-order analyses of the scales: an animated-dominant and an attentive-supportive dimension. In another factor-analytic study, Sorenson and Savage (1989) reported similar results, labeling the dimensions dominance and supportiveness. 
Burgoon and Hale $(1984,1987)$ took the same approach of reviewing a vast amount of theories and research on relational communication to find underlying themes (Osgood, Suci, and Tannenbaum, 1957; Smith, 1974, and many others). In several validation studies, they synthesized the different concepts to seven dimensions of a Relational Message Scale (RMS; cf. Table 1) (Burgoon and Hale, 1987). Although not explicitly defining the term communication style, they focused on describing and classifying the relational messages persons convey when interacting, which is an important aspect of communication behavior. In a more recent study, Dillard, Solomon, and Palmer (1999) were able to reduce the RMS to two fundamental factors, namely dominance and affiliation.

Contrary to the detailed and synthesizing approaches of Norton (1983) and Burgoon and Hale (1984), several industrial psychologists (Bolton and Bolton, 1984; Lashbrook and Lashbrook, 1979; Merrill and Reid, 1981) developed the Social Style Model (SSM) based on two fundamental dimensions of social behavior: assertiveness and responsiveness. While the first dimension represents how dominantly and self-confidently a person communicates, the latter dimension focuses on emotional reactions to communication. Combining different values of the two core dimensions leads to four social styles: amiable (high resp./low assert.), analytical (low resp./low assert.), driver (low resp./high assert.), and expressive (high resp./high assert.) The ability to change style under acute pressure has been introduced as a third social dimension called versatility (Merrill and Reid, 1981), also referred to as the technique of style-flexing (Bolton and Bolton, 1984). Compared to its intensive application in the private sector, empirical tests of the model have only rarely been reported (Lashbrook and Lashbrook, 1979; Prince, 1986; Snavely and McNeill, 2008).

Snavely and McNeill (2008) examined the relationships between communicator style and social style with the goal of integrating both concepts into one model. They factor-analytically confirmed the social style dimensions and some of the communicator style dimensions and reduced the resulting components to three dimensions: emotive, assertive, and relaxed.

Research on communication style in cross-cultural communication has yielded a two-level model that integrates first-order and second-order dimensions. Hall (1976) differentiated between low-context communication (LC) and high-context communication (HC): LC involves sending direct and explicit messages, whereas $\mathrm{HC}$ implies transmitting indirect and contextualized messages that need to be interpreted by the recipient. LC has been associated with individualistic cultures and $\mathrm{HC}$ with collectivistic cultures (Kapoor, Hughes, Baldwin, and Blue, 2003). Gudykunst et al. (1996) described HC and LC style using eight dimen- 
Table 1. Communication style measures.

\begin{tabular}{|c|c|c|c|c|c|}
\hline \multirow[t]{2}{*}{ Scale } & $\begin{array}{l}\text { Communica- } \\
\text { tor Style } \\
\text { Measure } \\
\text { (CSM) }\end{array}$ & $\begin{array}{l}\text { Relational } \\
\text { Message Scale } \\
\text { (RMS) }\end{array}$ & $\begin{array}{l}\text { Social Styles } \\
\text { Model } \\
\text { (SSM) }\end{array}$ & $\begin{array}{l}\text { Communica- } \\
\text { tion Style } \\
\text { Scale } \\
\text { (CSC) }\end{array}$ & $\begin{array}{l}\text { Sociocom- } \\
\text { municative } \\
\text { Style } \\
\text { (SCS) }\end{array}$ \\
\hline & $\begin{array}{l}\text { (Norton, } \\
1983 \text { ) }\end{array}$ & $\begin{array}{l}\text { (Burgoon and } \\
\text { Hale, 1987) }\end{array}$ & $\begin{array}{l}\text { (Bolton and } \\
\text { Bolton, 1984; } \\
\text { Lashbrook } \\
\text { and Lash- } \\
\text { brook, 1979; } \\
\text { Merrill and } \\
\text { Reid, 1981) }\end{array}$ & $\begin{array}{l}\text { (Gudykunst } \\
\text { et al., 1996) }\end{array}$ & $\begin{array}{l}\text { (Richmond } \\
\text { and Martin, } \\
\text { 1998) }\end{array}$ \\
\hline $\begin{array}{l}\text { Styles } \\
\text { (first-order } \\
\text { factors) }\end{array}$ & $\begin{array}{l}\text { Dominant, } \\
\text { Contentious, } \\
\text { Attentive, } \\
\text { Open, } \\
\text { Friendly, } \\
\text { Dramatic, } \\
\text { Animated, } \\
\text { Impression } \\
\text { leaving, } \\
\text { Relaxed }\end{array}$ & $\begin{array}{l}\text { Immediacy/ } \\
\text { Affection, } \\
\text { Similarity/ } \\
\text { Depth, } \\
\text { Receptivity/ } \\
\text { Trust, } \\
\text { Composure, } \\
\text { Formality, } \\
\text { Dominance, } \\
\text { Equality }\end{array}$ & $\begin{array}{l}\text { Expressive, } \\
\text { Driver, } \\
\text { Amiable, } \\
\text { Analytical }\end{array}$ & $\begin{array}{l}\text { Infer mean- } \\
\text { ing, } \\
\text { Indirect/ } \\
\text { Ambiguous, } \\
\text { Interpersonal } \\
\text { sensitivity, } \\
\text { Dramatic, } \\
\text { Use of } \\
\text { feelings, } \\
\text { Openness, } \\
\text { Preciseness, } \\
\text { Silence }\end{array}$ & $\begin{array}{l}\text { Competent, } \\
\text { Aggressive, } \\
\text { Submissive, } \\
\text { Incompetent, }\end{array}$ \\
\hline \multirow[t]{3}{*}{$\begin{array}{l}\text { Dimensions } \\
\text { (second- } \\
\text { order } \\
\text { factors) }\end{array}$} & $\begin{array}{l}\text { Attentive- } \\
\text { supportive, } \\
\text { Animated- } \\
\text { dominant } \\
\text { (Hansford and } \\
\text { Hattie, 1987) }\end{array}$ & \multirow[t]{3}{*}{$\begin{array}{l}\text { Dominance, } \\
\text { Affiliation } \\
\text { (Dillard et al., } \\
\text { 1999) }\end{array}$} & \multirow[t]{3}{*}{$\begin{array}{l}\text { Assertiveness, } \\
\text { Responsive- } \\
\text { ness, } \\
\text { Versatility }\end{array}$} & $\begin{array}{l}\text { Verbal } \\
\text { engagement, } \\
\text { Attentiveness, } \\
\text { Feelings and } \\
\text { silence } \\
\text { (Leung and } \\
\text { Bond 2001) }\end{array}$ & \multirow[t]{3}{*}{$\begin{array}{l}\text { Assertiveness } \\
\text { Responsive- } \\
\text { ness }\end{array}$} \\
\hline & $\begin{array}{l}\text { Dominance, } \\
\text { Supportive- } \\
\text { ness } \\
\text { (Sorenson and } \\
\text { Savage, 1989) }\end{array}$ & & & $\begin{array}{l}\text { High- } \\
\text { Context Com- } \\
\text { munication, } \\
\text { Low-Context }\end{array}$ & \\
\hline & $\begin{array}{l}\text { Emotive, } \\
\text { Assertive, } \\
\text { Relaxed } \\
\text { (Snavely and } \\
\text { McNeill, 2008) }\end{array}$ & & & $\begin{array}{l}\text { Communica- } \\
\text { tion } \\
\text { (Park and } \\
\text { Kim, 2008) }\end{array}$ & \\
\hline
\end{tabular}

sions extracted from a factor analysis of 158 communication style items, later referred to as the Communication Style Scale (CSS; cf. Table 1). Empirical studies confirmed the hypotheses that indirect and ambiguous communication, interpersonal sensitivity, and positive perceptions of si- 
lence are associated with $\mathrm{HC}$, whereas inferring meaning, use of feelings as well as dramatic, open, and precise communication are associated with LC (Gudykunst et al., 1996; Park and Kim, 2008). In another study, Leung and Bond (2001) extracted three second-order factors: verbal engagement, attentiveness to the other, and feelings and silence. Thus, although researchers differ in the number of extracted factors, results point to the fact that the eight dimensions of the CSS can be reduced to a few higher-order factors.

Contrary to these theory-driven approaches, de Vries et al. (2009) used a lexical approach that had previously been successfully applied to identify the Big Five personality factors (Goldberg, 1992). The goal of their study was to discover underlying factors in the variety of adjectives and verbs that are used to describe communication behavior. From a list of 744 adjectives and 837 verbs de Vries et al. (2009) extracted seven factors: preciseness, reflectiveness, expressiveness, supportiveness, emotionality, niceness, and threateningness. However, the factor reflectiveness was less stable across samples than the other factors. Expressiveness, a blend of supportiveness and threateningness, as well as preciseness, proved to be the most fundamental factors in the study (de Vries et al., 2009, p. 189). These factors also were among those which showed the strongest relationships to the CSS scales (de Vries et al., 2009, pp. 193-196).

Summing up, in all the concepts discussed in this section, communication styles are regarded as stable behavioral patterns. However, the taxonomies differ in the degree of detail and the number of proposed dimensions.

\section{Communication styles as personality traits}

In contrast to the behavioral tradition of research on communication styles, McCroskey and colleagues are mainly interested in the empirical relations between personality traits and communicative behavior. Fundamental to their research is the assumption that communication behavior is directly influenced by the personality of an individual and that it has a biological base (Beatty and McCroskey, 1998, pp. 46-52).

Scholars of this research tradition regard personality and communication as "inherently intertwined" (Daly and Bippus, 1998, p. 22) or "close relative[s]" (Andersen, 1987). Richmond and Martin (1998) defined communication style as the disposition of a person to communicate in a certain way. However, definitions remain rather unclear on whether communication style is understood as a personality trait or as a construct derived from personality. Research projects study the relationship between personality and communication behavior, often focusing on single 
communicator traits such as argumentativeness (Infante and Gorden, 1989; Rancer, 1998) or willingness to communicate (MacIntyre, 1994).

In this research tradition, the only comprehensive taxonomy of communication styles was presented by Richmond and McCroskey (1990). They introduced the scales of Sociocommunicative Style (SCS) and Sociocommunicative Orientation (SCO) that have been applied in a number of empirical studies (e.g., Cole and McCroskey, 2000; Thomas, Richmond, and McCroskey, 1994), many of them in the field of educational communication (Aylor and Oppliger, 2003; Mottet and Beebe, 2006; Wanzer and McCroskey, 1998). SCO characterizes the self-perception of an individual of his or her own communication style, whereas SCS specifies how other persons perceive that individual.

The dimensions are the same as in the Social Styles Model, assertiveness and responsiveness, but the labels of the taxonomy differ. Different values on the two core dimensions are combined, resulting in the styles competent (high assert./high resp.), aggressive (high assert./low resp.), submissive (low assert./high resp.), and incompetent (low assert./low resp.). Cole and McCroskey (2000) presented reasonable correlations between $\mathrm{SCO}$ and personality traits.

Personality-oriented research on communication styles has been criticized for failing to produce an integrative and comprehensive model of communication-related variables (Daly, 2002; Daly and Bippus, 1998). Scholars specifically blamed the research tradition for only accumulating a variety of loosely related studies: "Each individual investigator selects her or his favorite trait and proceeds to explore the measurement, manifestations, or consequences of the disposition without much regard for how it fits within some larger domain of communication-related traits" (Daly and Bippus, 1998, p. 25). Furthermore, it has been criticized that, in traditional research on interpersonal communication, many interrelated variables are examined separately from each other, whereas relationships between constructs are neglected (Giles and Street, 1994, pp. 134-142).

\section{Embedding communication styles into the Five-Factor Theory}

In the previous sections, approaches to communication styles have been distinguished by the way researchers define the concept. On the one hand, scholars in the behavior-based tradition interpret communication styles as learned patterns of behavior. This often includes the belief that styles can be trained and adapted to different contexts. On the other hand, researchers of the personality-oriented perspective regard styles as based on personality traits that are at least partly genetically determined. The discussion resembles a well-known dispute in personality research 
that is often referred to as the person-situation or the nature-nurture debate (Epstein and O'Brian, 1985).

It should be noted that the division between behavior-oriented and personality-oriented approaches to communication style is only conceptual. In fact, overlaps of both research traditions exist. For example, Leung and Bond (2001) were able to demonstrate the predictive power of personality traits for communication styles measured with Gudykunst et al.'s (1996) CSS. Nevertheless, cross-references between the two research traditions are not frequent, which allows for them to be seen as two distinct schools of thought.

Current personality research offers a perspective for a definition of communication style with which both research traditions might agree. McCrae and Costa propose a meta-theoretical framework for personality theories that also helps one to better understand the theoretical context of communication styles: the Five-Factor Theory of Personality (FFT; McCrae and Costa, 1996; McCrae et al., 2000). According to the authors, it encompasses most of the variables with which personality theories have been concerned (McCrae and Costa, 1996, p. 65). The authors assume that biological bases influence the basic tendencies of personality: neuroticism, extraversion, openness to experience, agreeableness, and conscientiousness (McCrae et al., 2000). These basic tendencies are specific to each person, stable across time, and largely inheritable. Individuals behave in a way that is consistent with their predispositions and thus develop characteristic adaptations. These can be patterns of thoughts and feelings - such as attitudes or personal strivings -, patterns of behavior, or a specific self-concept. Characteristic adaptations are more closely linked to motivation, goals, and social roles than general traits (McAdams and Pals, 2006). They are not only influenced by the basic tendencies of an individual, but also by external influences such as cultural and social norms, life events, and situational factors and are therefore more susceptible to changes (McCrae and Costa, 1996, p. 74). McAdams and Pals (2006) even argue that some characteristic adaptations are rather socially shaped than trait-based. Along with external influences, characteristic adaptations directly influence the objective biography, e.g., the observable behavior of a person (McCrae and Costa, 1996).

When applying the FFT to communication theory, communication styles may be interpreted as characteristic adaptations (cf. Figure 1). This would acknowledge that communication styles are characteristic and relatively stable behavioral patterns, but influenced by personality, which in turn is dependent on individual biological bases. This means that a person will develop a communication style that is consistent with his or her basic personality traits. For example, an agreeable person will talk 


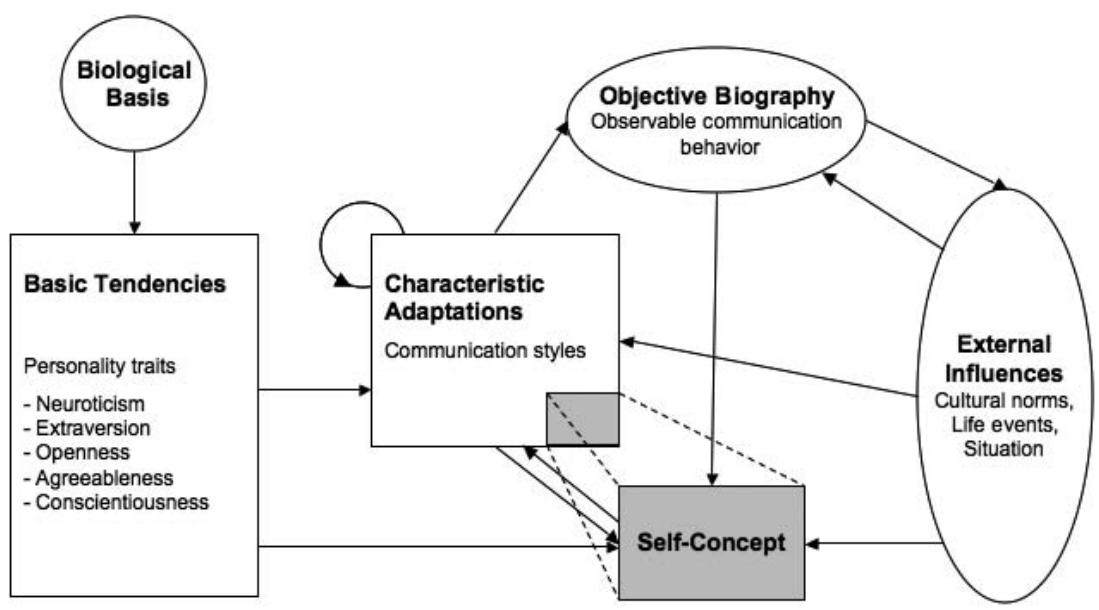

Figure 1. Applying the Five-Factor Theory of personality to define communication styles.

Note: Framework adapted from McCrae et al. (2000).

in a friendly and polite way rather than behave aggressively. However, the specific development of his or her communication style is not predetermined by genes and personality. It is also heavily influenced by education, culture, and the environment in which that person lives. Teachers, for example, might change their communication style to a more assertive pattern than before having this specific social role. Cultural and social influences might also superimpose personality traits. For example, a person may have a trait-based tendency to display emotions, but lives in a culture in which people have been taught not to do so. Whether or not this person behaves according to the dispositional or learned tendencies is then part of his or her communication style.

Communication style is also closely associated with a person's selfconcept, e.g., individuals perceiving themselves as independent from others (Markus and Kitayama, 1991) might communicate more assertively than individuals with a more interdependent self-concept. Finally, communication style also influences a person's objective biography of communication behavior. As it describes the way an individual communicates typically most of the time and in most situations, the specific observable communication behavior will mostly be consistent with style. However, in some cases, behavior might deviate from style due to specific situational influences, e. g., conflicts or pressure.

Thus, understanding communication styles as characteristic adaptations is a helpful strategy to integrate the behavioral as well as the per- 
sonality perspective. The framework helps to embed the concept of communication style in a larger theoretical system, thereby clarifying relations with other constructs such as personality and culture.

Applying FFT to communication style is also supported by empirical findings in the field. On the one hand, results of neurobiological and twin research suggest that genetic bases significantly influence personality structures (Buss, 1990; Harner, 1997; Heath, Neale, Kessler, Eaves, and Kendler, 1992; Riemann, Angleitner, and Strelau, 1997; Zuckerman, 1995) and behavioral patterns (Boomsma, Anokhin, and Geus, 1997; Cappella, 1991). Similarly, twin studies in the field of communication (Beatty, Heisel, Hall, Levine, and La France, 2002; Horvath, 1998) have shown that communicative tendencies are largely inherited. Although studies on sex differences in communicator style have yielded ambiguous results (Montgomery and Norton, 1981; Talley and Richmond, 1980), Bodary and Miller (2000) have shown that communication preferences vary with hemispheric brain dominance. Several researchers have also shown that personality and communication styles are strongly related (Beatty and McCroskey, 1998; Leung and Bond, 2001; McCroskey, Heisel, Richmond, and Hayhurst, 2004; Weaver, 2005). Therefore, personality traits might serve as mediators between biological predispositions and communication styles.

On the other hand, there are studies showing that certain communication styles can be trained (e.g., Barlow, Hansen, Fuhriman, and Finley, 1982; Lewittes and Bem, 1983) and thereby supporting the situational view of behavior-based research. Cross-cultural research has produced rather contradictory findings on the question of whether individuals are able to adapt their style to interaction partners from other cultures or not (Adler and Graham, 1989; Pekerti and Thomas, 2003; Rao and Hashimoto, 1996; Tse, Francis, and Walls, 1994). However, scholars have been able to trace important cultural differences in communication style. There are numerous studies that report significant relationships between culture and self-construal, culture and communication style as well as self-construal and communication style (e.g., Ellis and Wittenbaum, 2000; Gudykunst et al., 1996; Kapoor et al., 2003; Markus and Kitayama, 1991).

To sum up, we propose a definition of communication style that draws on the FFT (McCrae and Costa, 1996) as well as on Norton's classic definition (1983):

Proposition 1: Communication styles are characteristic adaptations of personality and describe the way one verbally and nonverbally interacts with others. 


\section{Integrating communication styles into the Interpersonal Circumplex}

The similarities between taxonomies in describing the construct of communication style are remarkable. SSM (Merrill and Reid, 1981) and SCS (Richmond and Martin, 1998) are based on the two key dimensions assertiveness and responsiveness. Other models with more dimensions have been linked to these dimensions or have been reduced to similar secondorder factors (Burgoon and Hale, 1987; Hansford and Hattie, 1987; Leung and Bond, 2001; Park and Kim, 2008). Although de Vries et al. (2009) favor a seven-factor solution, the first two fundamental factors in their lexical study - expressiveness and supportiveness/threateningness - are very similar to the personality factors extraversion and agreeableness as well as the interpersonal factors dominance and love. Assertiveness and responsiveness therefore are two stable themes that communication style researchers have found repeatedly across samples, methods, and research traditions.

Research on interpersonal behavior in general has often resulted in similar fundamental themes. For example, Mehrabian (2007) developed a model of nonverbal behavior consisting of three orthogonal dimensions: Evaluation (or positiveness) is a sympathy factor, very similar to the responsiveness dimensions in the communication styles models. Status (or potency) resembles the assertiveness dimension. The third dimension is named responsiveness, but rather describes the activity level of nonverbal communication (e.g., facial activity or speech rate).

Rahim (1983) differentiated conflict styles along two basic dimensions, concern for self and concern for others, that are very similar to the individualism and collectivism dimensions in cross-cultural research. In their socio-analytic theory, Hogan and Hogan (2002) distinguished two similar basic themes for describing motives in interpersonal behavior: getting ahead and getting along. In the Bem Sex Role Inventory (BMSRI; Bem, 1974) such basic dimensions were interpreted as masculine and feminine sex roles. Research on leadership styles has drawn on the fundamental dimensions task orientation (initiating structure) and person orientation (consideration; Blake and Mouton, 1964; Stogdill, 1974).

Spitzberg and Cupach (1974) gave an extensive review of 75 instruments for measuring interpersonal competence in their Handbook of Interpersonal Competence Research. In most approaches, they were able to identify three fundamental themes: control, collaboration, and adaptability. These themes very much resemble the dimensions assertiveness, responsiveness, and versatility.

In contrast to the assertiveness and responsiveness dimensions, which are the basic coordinates of the models above, style flexibility or versatility is not a dimension that describes communicative behavior, but rather 
characterizes how an individual deals with his or her own communication style (Muck, 2003, p. 247). Similarly, positive perception of silence and use of feelings, combined in the third higher-order factor proposed by Leung and Bond (2001), rather describe intrapersonal affects and cognitions about communication than communication behavior itself (de Vries et al., 2009, p. 197). These factors should therefore be seen as dimensions beyond the description and distinction of communication styles. Dillard et al. (1999) distinguished substantive variables such as dominance and affiliation from intensifier variables such as involvement. Following this argument, the activity dimension in nonverbal communication (Mehrabian, 2007) as well as the relaxation dimension found by Snavely and McNeill (2008) might also qualify as intensifier variables because they can be understood as specific forms of involvement.

To date, assertiveness and responsiveness constitute the two main dimensions in communication style research. Other factors have not been replicated comparably often across studies. Based on the current state of research, we propose to describe communication styles by only two substantive dimensions:

Proposition 2: Communication styles are described by two fundamental dimensions: assertiveness and responsiveness.

The danger of using just two dimensions lies in oversimplifying the realm of possible distinctions (Burgoon and Hale, 1984). A compromise between parsimony and preciseness is reached by arranging different styles in a circular space defined by two fundamental dimensions. This concept has been developed and elaborated in research on interpersonal behavior and is called the Interpersonal Circumplex (IPC; Leary, 1957; Wiggins, 1979). It describes interpersonal behavior using a circular model based on two orthogonal dimensions: dominance and love.

Leary and colleagues were the first researchers to apply a circular model to describe interpersonal behavior (Freedman, Leary, Ossorio, and Coffey, 1951; Leary, 1957). Their circumplex locates sixteen sectors of interpersonal behavior around a circle and has become the basis for several other models following the same logic. Among these, the IPC by Wiggins (1979) in its revised form (Wiggins, Trapnell, and Phillips, 1988) is the most elaborated and validated (cf. Figure 2).

The IPC consists of eight sectors (octants), based on two orthogonal and therefore independent basic dimensions: dominance and love. The sectors are specific combinations of the two core dimensions and are called facets of the IPC. This way, the IPC includes second-order factors (dimensions) and first-order factors (facets) in one model.

The IPC assumes a specific correlation structure of the octants. Adjacent sectors should correlate strongly positively, opposite sectors strongly negatively, and orthogonal sectors should not correlate signifi- 


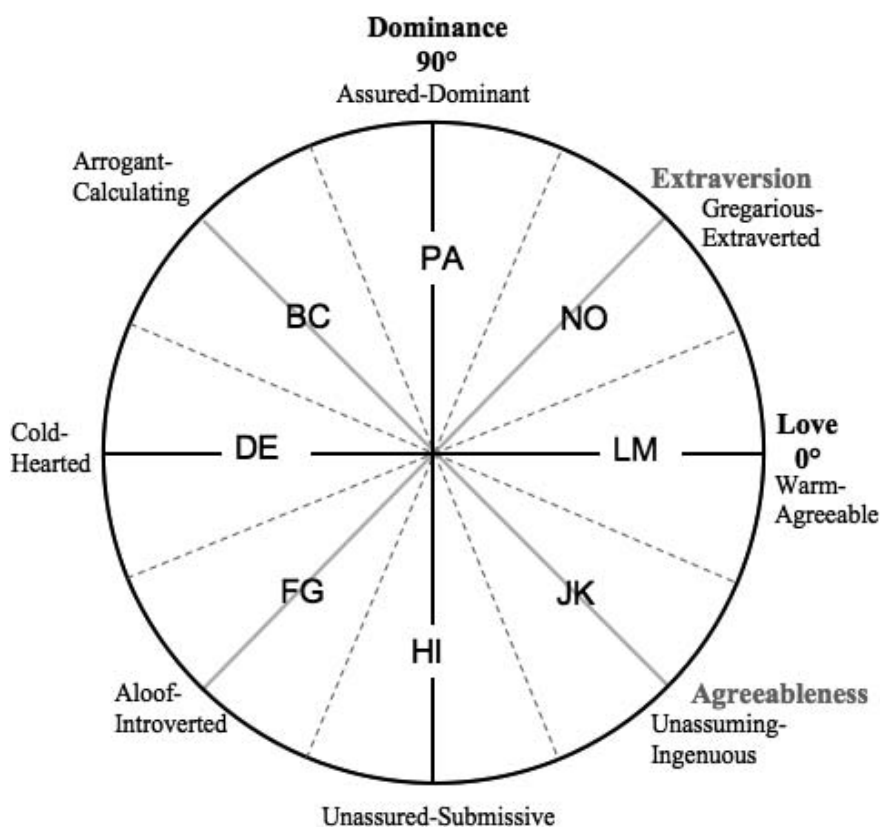

Figure 2. The Interpersonal Circumplex as an integrative framework for interpersonal traits.

Note: Figure referring to Wiggins et al. (1988) and McCrae and Costa (1989).

cantly at all. Wiggins and his colleagues have extensively tested and optimized the circumplex structure of their IPC measure: the Revised Interpersonal Adjective Scales (IAS-R; Wiggins, Phillips, and Trapnell, 1989; Wiggins et al., 1988). This instrument forms an almost perfect circumplex with two factors both accounting for about the same percentage of variance.

Several scholars have provided evidence that the whole interpersonal domain is structured in a circular way (de Raad and Hofstee, 1993; Muck, 2003; Wiggins and Broughton, 1991). This does not only apply to verbal behavior: scholars were also able to map nonverbal behaviors on the IPC (Gifford, 1991; Myllyniemi, 1997). McCrae and Costa (1989) have examined relationships between the IPC and the Five-Factor-Model of Personality (FFM), showing that the interpersonal personality factors extraversion and agreeableness can be interpreted as the axes dominance and love shifted clockwise by about $30^{\circ}$ to $45^{\circ}$ (cf. Figure 2). Although extraversion and agreeableness are most obviously aligned with the IPC meta-concepts, scholars have also found relationships between IPC dimensions and the other three personality factors. For example, Schmidt, 
Wagner, and Kiesler (1999) reported positive correlations of openness to experience as well as conscientiousness with the love dimension and negative correlations of neuroticism with both dimensions of the IPC. Other scholars observed neuroticism being associated with submissive behavior as well (di Blas, Forzi, and Peabody, 2000; Kiesler, 1983; Whiteman, Bedford, Grant, Fowkes, and Deary, 2001).

Against this background, it seems surprising that only the early taxonomies of communication behavior (Burgoon and Hale, 1984; Norton, 1983) explicitly refer to the IPC. Knapp (1978) proposed the IPC as a framework for studying communication styles more than thirty years ago. Today, the IPC is an established and empirically proven model in interpersonal research so that the advantage of relating communication style research to it is even more evident.

Both key dimensions used in research on communicative behavior assertiveness and responsiveness - are close relatives to the factors dominance and love. The adjective 'assertive' is part of the final set of the IAS-R and has been located within the IPC by Wiggins et al. (1988) at $86.5^{\circ}$. The adjective 'responsive' is not used in the IAS-R, but the word accommodating at $356^{\circ}$ is close in its meaning. We propose to embed the dimensions assertiveness and responsiveness in the circular model of the IPC.

Proposition 3: The communication-specific dimensions assertiveness and responsiveness are representations of the fundamental dimensions dominance and love in the IPC.

Another argument for the parsimony of the IPC is the fact that it is able to incorporate intensity variables without introducing a separate dimension. For this purpose, vector lengths are used to measure the intensity of individual scores in the circumplex ranging from the moderate and generally adaptive to the extreme and often maladaptive (Moskowitz and Zuroff, 2004; Wiggins et al., 1989). This way, also communication variables like versatility or relaxation might be integrated into the IPC.

Nevertheless, some scholars doubt that the IPC covers the whole interpersonal domain. For example, Widiger and Hagemoser (1997) claimed that the IPC is too narrow and especially lacks an affective component. De Vries et al. (2009, p. 199) raise a similar concern for the communication style domain. They assume that the factors emotionality and preciseness of their lexical seven-factor-solution are not well represented by the IPC. However, some facts may point to relationships between those factors with the IPC. For example, emotional expressivity is a dimension of the Social Skills Inventory (Riggio and Carney, 2003) and has been located in the IPC at $52^{\circ}$ (Gurtman, 1999) or $66^{\circ}$ (Muck, 2003, p. 337), respectively. Concerning the factor preciseness, de Vries et al. (2009) re- 
port strong correlations between the lexical dimension and the CSS factor preciseness. Other researchers have already related CSS and CSM preciseness to the factors dominance (Sorenson and Savage, 1989) and verbal engagement (Leung and Bond, 2001). The empirical relationships of the lexical communication style factors with the IPC dimensions still have to be studied.

Following the logic of the IPC, communication styles should be regarded as facets differing in their correlations with the two key dimensions. This might explain why authors come to different style labels despite basing their taxonomies on the same fundamental dimensions. For example, a highly responsive, but less assertive communication style is called amiable in the SSM (Bolton and Bolton, 1984; Merrill and Reid, 1981) or submissive in the SCS taxonomy (Richmond and Martin, 1998). In this case, it seems that the authors each emphasize different facets of the IPC by blending the underlying dimensions differently.

Proposition 4: Communication styles are facets of the underlying dimensions assertiveness and responsiveness and conform to a circumplex structure.

Future studies should try to empirically locate the different scales and styles in the IPC and clarify the relations between the different styles. They should also test the factor structure of the scales to validate the assumptions of a circular structure for communication styles as well. As this assumption has been confirmed for other interpersonal scales (Alden, Wiggins, and Pincus, 1990; de Raad, 1999; Dryer and Horowitz, 1997; Locke, 2000; Muck, Höft, Hell, and Schuler, 2006; Trobst, 2000), it can reasonably be assumed that this should also apply to communicative behavior. Future research could thus lead to a validated circumplex of communication styles and a standard instrument for measuring these.

\section{Towards a circumplex model of communication styles}

Although until now no studies on the circumplex structure of communication styles have been conducted, results from the existing body of research already give hints where the different communication styles might be located in such a model. Table 2 shows the factor loadings of communication style dimensions on second-order factors that researchers have found up to date. In the column "factor 1" all dimensions are listed that are associated with the IPC dominance factor, whereas "factor 2" subsumes all dimensions aligned with the IPC love factor. Each group of styles contains all styles with a similar factor loading structure and/ or similar labels. The evidence presented in Table 2 is summarized in a proposed communication style circumplex with eight distinct sectors in Figure 3. 


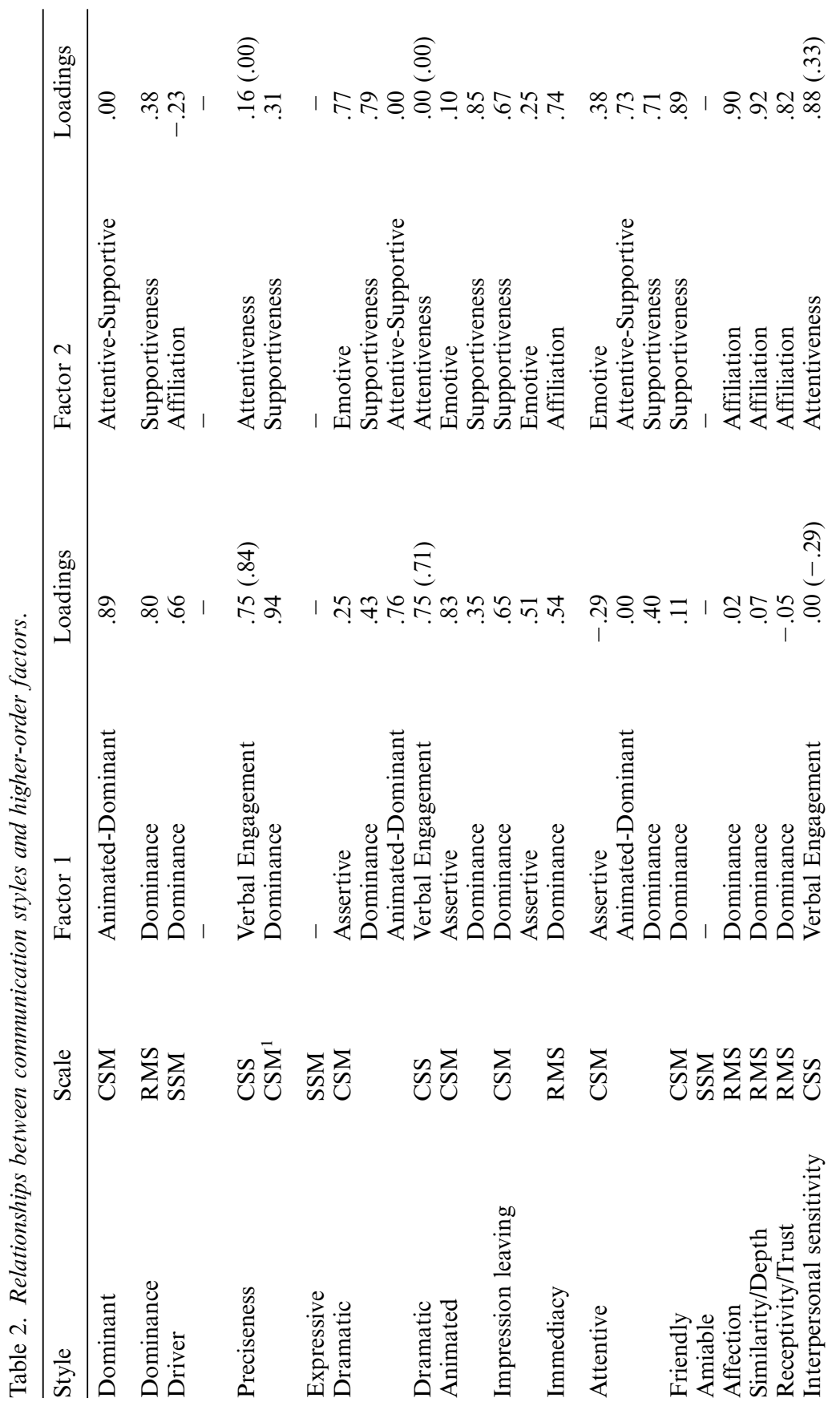




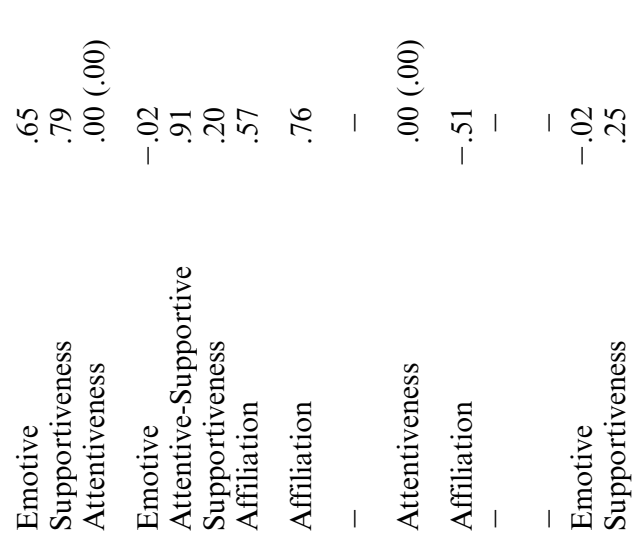

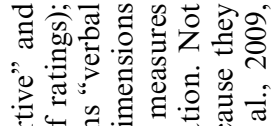

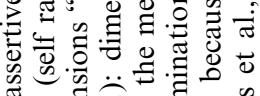

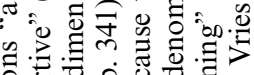

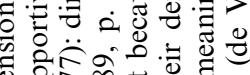

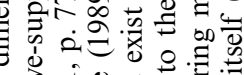

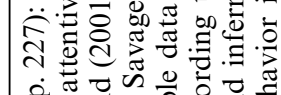

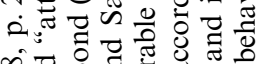

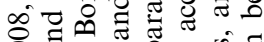

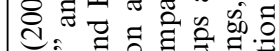

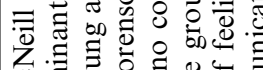

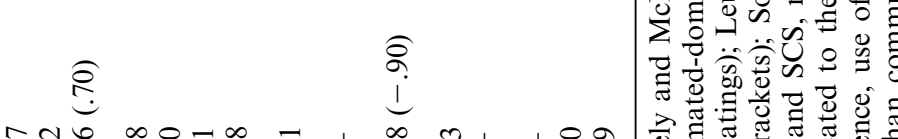

군

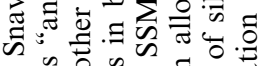

论

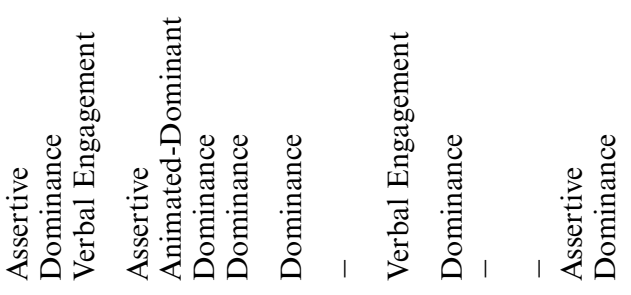

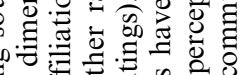

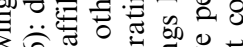

응의

2 2 政0

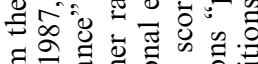

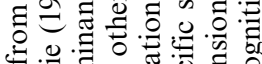

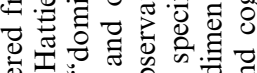

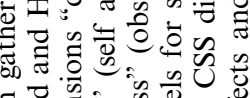

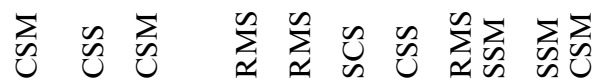

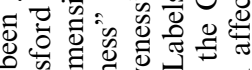

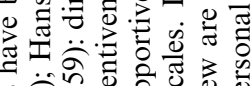

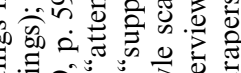

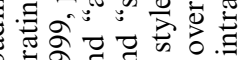




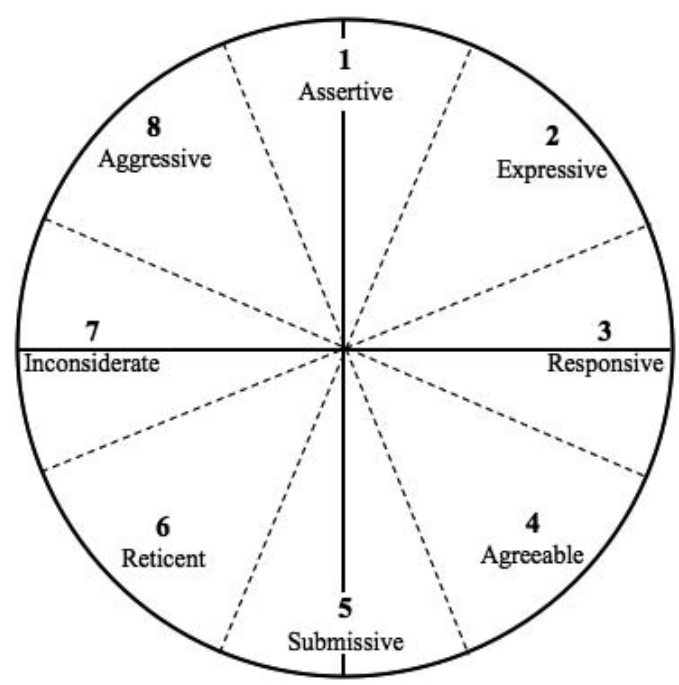

Figure 3. Towards a Communication Style Circumplex.

The dominant styles can be clearly assigned to the sector of the dominance factor in the IPC or the assertiveness sector in a Communication Style Circumplex (CSC). All researchers report high factor loadings on factor 1. Although results differ regarding the loadings on factor 2, dominant styles should be located in the topmost sector 1 . We propose to use the term assertive for these styles, because assertiveness is the dominance dimension of communication styles referred to by most communication style researchers. Preciseness also shows a high share of dominance or verbal engagement, and loads only moderately on the factors attentiveness or supportiveness. Therefore, it represents a more dominant communication style.

Styles of the next group predominantly show substantial loadings on both factors. They should therefore be located around the extraversion dimension in the IPC. Expressive is a suitable label, taken from the SSM, for these rather outgoing, dramatic, and animated styles. Wiggins and Broughton (1991) located the expressiveness scale of Hogan's Personality Inventory (1986) at $36^{\circ}$ in this sector.

The attentive and friendly styles of the CSM form another group with the dimensions affection, similarity/depth, and receptivity/trust of the RMS as well as interpersonal sensitivity of the CSS. With only a few exceptions, researchers report high loadings on the equivalents of the love factor and only negligible loadings on the dominance factor (Snavely and McNeill, 2008; Sorenson and Savage, 1989). These styles 
are labeled responsive because they are hypothesized to be located in the sector of the responsiveness dimension.

The allocation of the open and relaxed communication styles is less clear. Here, results differ from high loadings on both factors (Sorenson and Savage, 1989) to negative loadings on the dominance and positive loadings on the love factor (Leung and Bond, 2001; Snavely and McNeill, 2008). Therefore, according to the current state of research, these styles cannot be attributed to one specific sector although they should be located on the right part of the circle. As stated above, relaxation might also be understood as an intensifier variable.

Little data is available on the remaining styles. For the equality dimension of the RMS, Dillard and colleagues (1999) reported highly positive loadings on the affiliation factor and moderately negative loadings on the dominance factor. This suggests locating equality in sector 4 of the CSC. Following the logic of the IPC (McCrae and Costa, 1989; Wiggins et al., 1988), communication styles of this sector should reflect an unassuming and agreeable personality. De Vries, van den Hooff, and de Ridder (2006) suggested the term agreeable for an equivalent style of team communication, the scale encompassing adjectives like patient, kind, and friendly. In the lexical study of de Vries et al. (2009), the niceness dimension describes this style best with marker adjectives like soft-hearted, kind, and pleasant. Following de Vries et al. (2006), we propose labeling these communication styles as agreeable.

To date, none of the existing communication styles shows the required factor loading structure to be located in sector 5. In theory, this sector should subsume submissive communication behaviors, which load strongly negatively on the assertiveness dimension and are not related to the responsiveness dimension. The label submissive for sector 5 of the communication style circumplex has been chosen, because Wiggins et al. (1988) label the negative pole of the dominance dimension 'unassuredsubmissive'.

At first sight, CSS indirect communication seems to be a feature of a submissive style as it loads highly negatively on the verbal engagement factor, but shows no relation to the attentiveness factor (Leung and Bond, 2001). However, verbal engagement should not be regarded as a pure dominance factor. De Vries et al. (2009) report negative correlations of CSS indirect communication with the factor expressiveness. Therefore, indirect communication should be interpreted as the negative pole of expressiveness rather than dominance. This is the reason why we attribute indirect communication to sector 6 in the CSC. In the IPC (Wiggins et al., 1988), this sector is titled aloof-introverted and also incorporates the adjective 'distant'. As a label summarizing the silent, restrained, and 
indirect ways to communicate, we propose the adjective reticent for this sector.

The negative pole of the responsiveness factor in sector 7 should load strongly negatively on the love factor without being related to dominance and its equivalents. In theory, this communication style should be cold and misanthropic without being dominant. According to the results of Leung and Bond (2001), the formality dimension of the RMS could be located in this sector. However, formality is only one aspect of the communication behavior in this sector that might be described using the IAS-R adjectives cold-hearted or cruel (Wiggins et al., 1988). We propose the label inconsiderate for sector 7, as it signifies a lack of warmth, responsiveness, and concern for others.

Finally, sector 8 constitutes the negative pole of the agreeableness dimension. Consequently, the aggressive and contentious styles should be located here as they are supposed to label unsupportive communication behavior paired with dominance. Support is given by Wiggins and Broughton (1991) who located several aggression scales between $104^{\circ}$ and $154^{\circ}$ in the IPC. Against this background, the positive factor loadings Sorenson and Savage (1989) found on the supportiveness factor for the CMS contentious style are quite surprising, but may be due to the particular sampling strategy of the authors. They only selected students with high scores on a leadership scale and thus high interpersonal competencies who therefore may have had superior abilities in combining assertiveness and supportiveness.

The next step would be to empirically validate the proposed model. For this purpose, a questionnaire for self- and other-rating communication styles should be developed. Table 3 presents some verbal sample items that could be included in such a questionnaire. Of course, nonverbal items could also be formulated for each sector. For example, "When he meets a friend, he enthusiastically embraces him" would describe a nonverbal expressive communication style.

With such an instrument, scholars would be able to examine the circumplex structure of communication styles. Classical techniques for internal circumplex validation comprise exploratory as well as confirmatory factor analyses and order relation tests of style intercorrelations. By calculating angle and vector length items can be located in the circumplex, which allows the theoretically assumed sector and the empirical sector of each item to be compared. Finally, external validity could be examined by studying empirical relationships of communication style to other measures, e.g., personality, self-concept, or satisfaction with interpersonal relationships in family or work contexts. More detailed accounts on circumplex validation techniques are given in Wiggins, Trapnell and Phillips (1988), Locke (2000), or Trobst (2000). 
Table 3. Sample items for the Communication Style Circumplex.

\begin{tabular}{lll}
\hline Sector & Style & Sample Item \\
\hline 1 & Assertive & $\begin{array}{l}\text { In most discussions, she dictates the issue to debate. } \\
\text { At parties, he is a social butterfly who easily chats with } \\
\text { strangers. }\end{array}$ \\
3 & $\begin{array}{l}\text { Respressive } \\
\text { She always has a comforting word if someone does not feel } \\
\text { well. }\end{array}$ \\
4 & Agreeable & $\begin{array}{l}\text { If someone attacks him, he tries to ease the situation rather } \\
\text { than defend himself. }\end{array}$ \\
5 & $\begin{array}{l}\text { Submissive } \\
\text { Reticent }\end{array}$ & $\begin{array}{l}\text { She usually agrees if others talk to her about their views. } \\
\text { While in the company of other people, he only talks when } \\
\text { someone directly addresses him. }\end{array}$ \\
7 & Inconsiderate & $\begin{array}{l}\text { She bluntly tells others that she is not interested in their } \\
\text { problems. } \\
\text { He overtly attacks people who disagree with his position. }\end{array}$ \\
\hline
\end{tabular}

Notes: The items are sample items for an other-rating questionnaire. For reasons of legibility we alternately use male and female subjects.

Apart from the questionnaire method, also observatory or lexical approaches might be taken to gather data on communication behavior. As questionnaires are theory-based, especially the lexical approach allows a completely different exploratory perspective (de Vries et al., 2009). Observatory methods as used by Benjamin (1996) are particularly interesting for recording real-life interactions between persons.

\section{Conclusion and future prospects}

In this paper, we have reviewed the existing literature on communication styles based on two research questions: how can we define and how can we distinguish communication styles? The answers from our literature review have been summarized in four propositions. With respect to the definition of communication styles, we have found two rather distinct approaches. Some researchers view communication styles as learnable behavioral patterns whereas others regard them as personality dispositions. As both approaches have their unique strengths, we propose defining communication styles as characteristic adaptations of personality (Proposition 1). This definition draws on the Five-Factor Theory of McCrae and Costa (1996) and acknowledges the diverse relationships between communication style, personality, culture, and observable behavior.

With respect to distinguishing communication styles, we have shown considerable similarities between the different taxonomies. Scholars of both research traditions structure communication styles along two key 
dimensions: assertiveness and responsiveness. Additionally, these or similar dimensions repeatedly emerged as second-order factors when analyzing existing communication style measures. Therefore, we conclude that communication styles are best described by these two dimensions (Proposition 2). Furthermore, assertiveness and responsiveness correspond closely to the basic coordinates, dominance and love, of the IPC (Wiggins, 1979), a widely-accepted taxonomy of interpersonal behavior. Thus, we propose integrating the dimensions assertiveness and responsiveness into the IPC as a reference model. We assume that the assertiveness dimension represents the dominance factor, whereas the responsiveness dimension represents the love factor (Proposition 3). We argue for understanding communication styles as blends of the underlying dimensions assertiveness and responsiveness conforming to a circumplex structure (Proposition 4).

Finally, a first tentative circumplex model of communication styles has been derived from the factor loading structures reported in the existing body of research. This heuristic model may serve as a frame of reference for future research. Furthermore, studies should empirically examine the relationships between the dimensions assertiveness and responsiveness, the IPC, and the different communication style taxonomies. This way, more empirical data will be available to evaluate whether a two-dimensional circumplex model is sufficient for distinguishing communication styles or if the model has to be extended. The development of a communication style questionnaire against the background of the proposed circumplex would be a promising step with respect to an empirical integration of future research. However, replicating results also by applying other methodological approaches such as lexical or observatory studies will be very important, as most communication style research until now has been theory-driven. This makes it vulnerable to the critique of just artificially reproducing similar higher-order factors because studies are based on earlier taxonomies and scales. To date, de Vries et al. (2009) have conducted the only lexical study in the field. It will be important to know if their findings will be supported by subsequent research. Furthermore, it would be promising to empirically relate the lexical factors to the IPC dimensions as well as to the communication style dimensions assertiveness and responsiveness. In personality research, both approaches, lexical as well as theory-driven, have resulted in the Big Five personality factors (Goldberg, 1992; McCrae and Costa, 1987). Thus, there are enough reasons to hope that communication style research might also succeed in developing a common framework across studies and methodological approaches.

A further prospect of IPC-based communication style research is that it also offers perspectives on the dyadic analysis of communication proc- 
esses, thus not only focusing on the communicator, but also on the recipient. Several scholars have developed empirically founded theories on complementary communication behavior, i.e., they have studied which interpersonal behaviors mutually reinforce each other (e.g., Gurtman, 2001; Kiesler, 1983; Strong et al., 1988; Tracey, Ryan, and Jaschik-Hermann, 2001). Combined with observatory methods, this concept could be used to specify matching communication behaviors for assuring effective communicative exchange. In the long run, this knowledge might substantially help to improve interpersonal communication in work and family contexts.

\section{Bionotes}

Annie Waldherr is Research Associate at the Institute for Media and Communication Studies, Free University of Berlin, Germany.

Peter M. Muck is Assistant Professor at the Faculty of Psychology and Sports Science, Bielefeld University, Germany.

\section{Note}

1. In their study, Sorenson and Savage (1989) used the original communicator style measure with twelve different styles. Precise is one of the styles that is not part of the final communicator style construct.

\section{References}

Andersen, P. A. (1987). The trait debate: A critical examination of the individual differences paradigm in interpersonal communication. In B. Dervin \& M. J. Voigt (Eds.), Progress in Communication Sciences (Vol. 8, pp. 47-82). Norwood, NJ: Ablex.

Baker, D. D. \& Ganster, D. C. (1985). Leader communication style: A test of average versus vertical dyad linkage models. Group and Organization Studies, 10, 242-259.

Bales, R. F. (1970). Personality and interpersonal behavior. New York: Holt, Rinehart and Winston.

Barlow, S., Hansen, W. D., Fuhriman, A. J., \& Finley, R. (1982). Leader communication style: Effects on members of small groups. Small Group Behavior, 13, 518531.

Beatty, M. J. \& McCroskey, J. C. (1998). Interpersonal communication as temperamental expression: A communibiological paradigm. In J. C. McCroskey, J. A. Daly, M. A. Martin, \& M. J. Beatty (Eds.), Communication and personality: Trait perspectives (pp. 41-67). Cresskill, NJ: Hampton.

Bednar, D. A. (1982). Relationships between communicator style and managerial performance in complex organizations: A field study. The Journal of Business Communication, 19, 51-76.

Bem, S. L. (1974). The measurement of psychological androgyny. Journal of Consulting and Clinical Psychology, 42. 
Benjamin, L. S. (1996). A Clinician-Friendly Version of the Interpersonal Circumplex: Structural Analysis of Social Behavior (SASB). Journal of Personality Assessment, 66, 248-266.

Blake, R. R. \& Mouton, J. S. (1964). The managerial grid: Key orientations for achieving production through people. Houston, TX: Gulf Publishing.

Bodary, D. L. \& Miller, L. D. (2000). Neurobiological substrates of communicator style. Communication Education, 49, 82-98.

Bolton, R. \& Bolton, D. G. (1984). Social stylelmanagement style. New York, NY: American Management Associations.

Burgoon, J. K. \& Hale, J. L. (1984). The fundamental topoi of relational communication. Communication Monographs, 51, 193-214.

Burgoon, J. K. \& Hale, J. L. (1987). Validation and measurement of the fundamental themes of relational communication. Communication Monographs, 54, 19-41.

Cole, J. G. \& McCroskey, J. C. (2000). Temperament and socio-communicative orientation. Communication Research Reports, 17, 105-114.

Daly, J. A. (2002). Personality and interpersonal communication. In M. L. Knapp \& J. A. Daly (Eds.), Handbook of interpersonal communication (pp. 133-180). Thousand Oaks, CA: Sage.

Daly, J. A. \& Bippus, A. M. (1998). Personality and interpersonal communication. In J. C. McCroskey, J. A. Daly, M. A. Martin, \& M. J. Beatty (Eds.), Communication and personality: Trait perspectives. Cresskill, NJ: Hampton.

de Raad, B. \& Hofstee, W. K. B. (1993). A circumplex approach to the five factor model: A facet structure of trait adjectives supplemented by trait verbs. Personality and Individual Differences, 15, 493-505.

de Vries, R. E., Bakker-Pieper, A., Alting Siberg, R., van Gameren, K., \& Vlug, M. (2009). The content and dimensionality of communication styles. Communication Research, 36, 178-206.

de Vries, R. E., van den Hooff, B., \& de Ridder, J. A. (2006). Explaining knowledge sharing: The role of team communication styles, job satisfaction, and performance beliefs. Communication Research, 33, 115-135.

di Blas, L., Forzi, M., \& Peabody, D. (2000). Evaluative and descriptive dimensions from Italian personality factors. European Journal of Personality, 14, 279-290.

Dillard, J. P., Solomon, D. H., \& Palmer, M. T. (1999). Structuring the concept of relational communication. Communication Monographs, 66, 49-65.

Epstein, S. \& O'Brian, E. J. (1985). The person-situation debate in historical and current perspective. Psychological Bulletin, 98, 513-537.

Freedman, M. B., Leary, T., Ossorio, A. G., \& Coffey, H. S. (1951). The interpersonal dimension of personality. Journal of Personality, 20, 143-161.

Gifford, R. (1991). Mapping nonverbal behavior on the interpersonal circle. Journal of Personality and Social Psychology, 61, 279-288.

Giles, H. \& Street, R. L. J. (1994). Communicator characteristics and behavior. In M. L. Knapp \& G. R. Miller (Eds.), Handbook of interpersonal communication ( $2^{\text {nd }}$ ed.). Thousand Oaks, CA: Sage.

Goldberg, L. R. (1992). The development of markers for the Big-Five factor structure. Psychological Assessment, 4, 26-42.

Gudykunst, W. B., Matsumoto, Y., Ting-Toomey, S., Nishida, T., Kim, K., \& Heyman, S. (1996). The influence of cultural individualism-collectivism, self construals, and individual values on communication styles across cultures. Human Communication Research, 22, 510-543.

Gurtman, M. B. (1999). Social competence: An interpersonal analysis and reformulation. European Journal of Psychological Assessment, 15, 233-245.

Hall, E. T. (1976). Beyond culture. New York, N. Y.: Doubleday. 
Hansford, B. C. \& Hattie, J. A. (1987). Perceptions of communicator style and selfconcept. Communication Research, 14, 189-203.

Hogan, R. (1986). Hogan Personality Inventory Manual. Minneapolis, MN: National Computer Systems.

Hogan, R. \& Hogan, J. (2002). The Hogan Personality Inventory. In B. de Raad \& M. Perugini (Eds.), Big Five Assessment (pp. 329-351). Göttingen: Hogrefe \& Huber.

Infante, D. A. \& Gorden, W. I. (1989). Argumentativeness and affirming communicator style as predictors of satisfaction/dissatisfaction with subordinates. Communication Quarterly, 37, 81-90.

Inglis, M. (1993). The communicator style measure applied to nonnative speaking teaching assistants. International Journal of Intercultural Relations, 17, 89-105.

Kapoor, S., Hughes, P. C., Baldwin, J. R., \& Blue, J. (2003). The relationship of individualism-collectivism and self-construals to communication styles in India and the United States. International Journal of Intercultural Relations, 27, 683-700.

Kettunen, T., Poskiparta, M., \& Liimatainen, L. (2000). Communicator styles of hospital patients during nurse-patient counseling. Patient Education and Counseling, $41,161-180$.

Kiesler, D. J. (1983). The 1982 interpersonal circle: A taxonomy for complementarity in human transactions. Psychological Review, 90, 185-214.

Knapp, M. L. (1978). Social intercourse: From greeting to goodbye. Boston, MA: Allyn Bacon.

Lashbrook, W. B. \& Lashbrook, V. J. (1979). The statistical adequacy of the social style profile. Eden Prairie, MN: Wilson Learning.

Leary, T. (1957). Interpersonal diagnosis of personality. New York: Ronald.

Leung, S.-K. \& Bond, M. H. (2001). Interpersonal communication and personality: Self and other perspectives. Asian Journal of Social Psychology, 4, 69-86.

Lewittes, H. J. \& Bem, S. L. (1983). Training women to be more assertive in mixedsex task-oriented discussions. Sex Roles, 9, 581-596.

Locke, K. D. (2000). Circumplex scales of interpersonal values: Reliability, validity, and applicability to interpersonal problems and personality disorders. Journal of Personality Assessment, 75, 249-267.

MacIntyre, P. D. (1994). Variables underlying willingness to communicate: A causal analysis. Communication Research Reports, 12, 241-247.

Markus, H. R. \& Kitayama, S. (1991). Culture and the self: Implications for cognition, emotion, and motivation. Psychological Review, 98, 224-253.

McAdams, D. P. \& Pals, J. L. (2006). A new Big Five: Fundamental principles for an integrative science of personality. American Psychologist, 61, 204-217.

McCrae, R. R. \& Costa, P. T. (1987). Validation of the five-factor model of personality across instruments and observers. Journal of Personality and Social Psychology, $52,81-90$.

McCrae, R. R. \& Costa, P. T. (1989). The structure of interpersonal traits: Wiggins' circumplex and the Five-Factor Model. Journal of Personality and Social Psychology, 56, 10 .

McCrae, R. R. \& Costa, P. T. (1996). Toward a new generation of personality theories: Theoretical contexts for the Five-Factor Model. In J. S. Wiggins (Ed.), The Five Factor Model of Personality: Theoretical perspectives (pp. 51-87). New York, NY: Guilford Press.

McCrae, R. R., Costa, P. T., Ostendorf, F., Angleitner, A., Hrebíckovà, M., Avia, M. D., et al. (2000). Nature over nurture: Temperament, personality, and life span development. Journal of Personality and Social Psychology, 78, 173-186.

Mehrabian, A. (2007). Nonverbal communication. New Brunswick: Aldine Transaction.

Merrill, D. W. \& Reid, R. H. (1981). Personal styles and effective performance. Radnor, PA: Chilton. 
Montgomery, B. M. \& Norton, R. (1981). Sex differences and similarities in communicator style. Communication Monographs, 48, 121-132.

Moskowitz, D. S. \& Zuroff, D. C. (2004). Flux, pulse, and spin: Dynamic additions to the personality lexicon. Journal of Personality and Social Psychology, 86, 880-893.

Muck, P. M. (2003). Der Interpersonale Circumplex als Grundlage einer Eigenschaftstheorie der Interpersonalität im beruflichen Kontext [ The interpersonal circumplex as a basis for a trait theory of the interpersonal domain for the occupational context]. Berlin: dissertation.de.

Myllyniemi, R. (1997). The interpersonal circle and the emotional undercurrents of human sociability. In R. Plutchik \& H. R. Conte (Eds.), Circumplex models of personality and emotions (pp. 271-295). Washington, DC: American Psychological Association.

Norton, R. (1978). Foundation of a communicator style construct. Human Communication Research, 4, 99-112.

Norton, R. (1983). Communicator Style: Theory, Applications and Measures (Vol. 1). Beverly Hills, California: Sage.

Osgood, C. E., Suci, G. J. \& Tannenbaum, P. H. (1957). The measurement of meaning. Urbana, IL: University of Illinois Press.

Park, Y. S. \& Kim, B. S. K. (2008). Asian and European American cultural values and communication styles among Asian American and European American college students. Cultural Diversity and Ethnic Minority Psychology, 14, 47-56.

Rahim, M. A. (1983). A measure of styles handling interpersonal conflict. Academy of Management Journal, 26, 368-376.

Rancer, A. S. (1998). Argumentativeness. In J. C. McCroskey, J. A. Daly, M. A. Martin, \& M. J. Beatty (Eds.), Communication and personality: Trait perspectives (pp. 149-170). Cresskill, NJ: Hampton.

Richmond, V. P. \& Martin, M. M. (1998). Sociocommunicative style and sociocommunicative orientation. In J. C. McCroskey, J. A. Daly, M. M. Martin, \& M. J. Beatty (Eds.), Communication and personality: Trait perspectives (pp. 133-148). Cresskill, NJ: Hampton.

Richmond, V. P. \& McCroskey, J. C. (1990). Reliability and separation of factors on the assertiveness-responsiveness measure. Psychological Reports, 67, 449-450.

Riggio, R. E. \& Carney, D. R. (2003). Social Skills Inventory. Mountain View, CA: Mind Garden.

Schmidt, J. A., Wagner, C. C. \& Kiesler, D. J. (1999). Covert reactions to Big Five personality traits: The Impact Message Inventory and the NEO-PI-R. European Journal of Psychological Assessment, 15, 221-232.

Schramm, W. (Ed.). (1954). The process and effects of mass communication. Urbana, IL: University of Illinois Press.

Schutz, W. C. (1958). FIRO: A three-dimensional theory of interpersonal behavior. New York: Holt, Rinehart and Winston.

Smith, W. J. (1974). Displays and messages in intraspecific communication. In S. Weitz (Ed.), Nonverbal communication (pp. 331-340). New York, NY: Oxford University Press.

Snavely, W. B. \& McNeill, J. D. (2008). Communicator style and social style: Testing a theoretical interface. Journal of Leadership and Organizational Studies, 14, $219-232$.

Sorenson, R. L. \& Savage, G. T. (1989). Signaling participation through relational communication: A test of the leader interpersonal influence model. Group Organization Management, 14, 325-354.

Spitzberg, B. H. \& Cupach, W. R. (1974). Handbook of interpersonal competence research. New York, NY: Springer. 
Stogdill, R. M. (1974). Handbook of leadership: A survey of theory and research. New York, NY: Free Press.

Talley, M. A. \& Richmond, V. P. (1980). The relationship between psychological gender orientation and communicator style. Human Communication Research, 6, $326-339$.

Thomas, C. E., Richmond, V. P., \& McCroskey, J. C. (1994). The association between immediacy and socio-communicative style. Communication Research Reports, 11, $107-114$.

Trobst, K. K. (2000). An interpersonal conceptualization and quantification of social support transactions. Personality and Social Psychology Bulletin, 26, 971-986.

Whiteman, M. C., Bedford, A., Grant, E., Fowkes, F. G. R., \& Deary, I. J. (2001). The five-factor model (NEOFFI) and the Personality Deviance Scales-Revised (PDS-R): Going around in interpersonal circles. Personality and Individual Differences, 31, 259-267.

Widiger, T. A. \& Hagemoser, S. (1997). Personality disorders and the interpersonal circumplex. In R. Plutchik \& H. R. Conte (Eds.), Circumplex models of personality and emotions (pp. 299-325). Washington, D. C.: American Psychological Association.

Wiggins, J. S. (1979). A psychological taxonomy of trait-descriptive terms: The interpersonal domain. Journal of Personality and Social Psychology, 37, 395-312.

Wiggins, J. S. \& Broughton, R. (1991). A geometric taxonomy of personality scales. European Journal of Personality, 5, 343-365.

Wiggins, J. S., Phillips, N., \& Trapnell, P. (1989). Circular reasoning about interpersonal behavior: Evidence concerning some untested assumptions underlying diagnostic classification. Journal of Personality and Social Psychology, 56, 296-305.

Wiggins, J. S., Trapnell, P., \& Phillips, N. (1988). Psychometric and geometric characteristics of the Revised Interpersonal Adjective Scales. Multivariate Behavioral Research, 23, 517-530. 